\title{
Practice of China's New High-level University of Science and Engineering's International Development: A Case Study of Dongguan University of Technology
}

\author{
Dun Liu ${ }^{1}$, Qinhua $\mathrm{Hu}^{2}$ \\ ${ }^{1}$ Institute of Higher Education Research, Dongguan University of Technology, Dongguan, 523015, China \\ ${ }^{2}$ Dongguan University of Technology, Dongguan, 523015, China
}

\begin{abstract}
Higher education' internationalization connects well with the Belt and Road Initiative and Guangdong-Hong Kong-Macao Greater Bay Area construction. New type of high-level university of science and engineering' international development is of great significance. Take Dongguan University of Technology as an example and analyze its strategy and practice. We find DGUT constructed an extensive and in-depth network of international cooperation, pushed forward multiple, characteristic and cross-border cooperation in running universities and colleges, created disciplines and subjects which have prominent advantages, attached importance to both external and internal training, enhanced internationalization ability of teachers and management teams.
\end{abstract}

Keywords: international development; university of science and engineering; practice

\section{Introduction}

With the rapid development of global society and economy, the rapid advancement of science and technology, and the deepening of Internet, big data, cloud computing and artificial intelligence, internationalization has become the general trend. In the field of education, the future development of institutions of higher learning cannot be separated from international strategic deployment and practical promotion. In April 2016, the General Offices of the CPC Central Committee and the State Council issued Several Opinions on Doing a Good Job in Opening Education to the Outside World in the New Era, emphasizing "to introduction high-quality foreign resources and deepen bilateral multilateral education cooperation." In July 2016, China's Ministry of Education issued the Promoting the Co-construction of the Belt and Road (B\&R) Initiative Education Action which requires "to carry out education connectivity cooperation and personnel training cooperation". In January 2017, China's State Council announced the 13th Five-Year Plan for the Development of National Education, which states that "the overall utilization of domestic and international educational resources, the extensive use of advanced international experience for reference, the further improvement of the level of education opening to the outside world, the resolution of difficult problems through reform and innovation and opening to the outside world, the stimulation of vitality and the promotion of development." In February 2019, the CPC Central

Copyright (C) 2019 by author(s) and Frontier Scientific Research Publishing Inc.

This work is licensed under the Creative Commons Attribution International License (CC BY 4.0).

$\mathrm{http}$ //creativecommons.org/licenses/by/4.0/ 
Committee and the State Council issued the Outline of the Development Plan for Guangdong-Hong Kong-Macao Greater Bay Area (GBA), which pointed out that the GBA should actively expand cooperation in education and other fields, build a high level of education and talents, and support the GBA in building an international education demonstration area. It can be seen that the internationalization of higher education, the B\&R Initiative education campaign and the coordinated development of education in the GBA have become hot topics that have attracted much attention and are bound to be carried out.

\section{New High-level University of Science and Engineering}

As an important driving force and key driver for the innovation, structural optimization and strength enhancement of the national higher education system, the construction and development of new high-level universities of science and engineering have attracted increasing attention from all walks of life. In 2015, Guangdong province launched the construction plan of high-level science and engineering universities, and decided to "focus on the construction of a number of high-level science and engineering universities and develop a number of science and engineering and applicationoriented key disciplines." In June 2017, the Ministry of Education convened the "Establishment of An Expert Group on Research and Practice of New Engineering and the First Working Meeting " in Beijing. The new engineering construction was fully started and systematically deployed. The "Guidelines for New Engineering Research and Practice Projects" (the Beijing Guidelines) were reviewed and approved, stating that "a number of new high-level science and engineering universities should be built." In July 2019, the Guangdong Provincial Department of Education, the Department of Science and Technology, and the Dongguan Municipal People's Government established Dongguan University of Technology as a demonstrative university for the construction of a new type of high-level university of science and engineering, pioneering a pilot project and playing a leading role.

\section{Literature Review of Related Studies in China}

The new type of high-level university of science and engineering is a major measure of the provincial higher engineering education reform under the background of "Double First-Class" and "New Engineering" in the country. It is also an innovative example of regional higher education led by the government and involving multiple subjects such as universities, enterprises and society. The internationalization strategy development of the new type of high-level university of science and engineering is of great significance. Based on the analysis of the existing literature, Ke Wang studied the deficiencies of the $B \& R$ Initiative for training talents in science and engineering, pointing out that the current training objective is vague and convergent, the scheme setting is traditional and single, the internationalization level is still limited, and the cooperation between universities and enterprises is not deep enough. Man Xu analyzed the current situation of foreign language culture construction, curriculum teaching, exchange and cooperation in the international development of universities of science and engineering. Jian-guang Sun discussed the connotation and requirements of the construction of internationalized college English curriculum system in local colleges of science and engineering. Yi Zhan explored the transformation and practical effect of students' ideological and political work under the influence of internationalization in universities of science and engineering. On the whole, different scholars have made certain discussions on the personnel training, curriculum system and foreign language culture construction, ideological and political work transformation of the internationalization development of universities of science and engineering. However, there is a lack of multi-level, allround, three-dimensional and systematic research on macro-strategic layout, meso-strategic design and micro-strategic implementation, and there is no research on the internationalization development of new high-level universities of science and engineering. Taking Dongguan University of Technology as an example, this paper discusses the internationalization strategy development of new high-level universities of science and engineering, and gets some thoughts and suggestions. 


\section{Case Study on Dongguan University of Technology}

Dongguan University of Technology (DGUT), established in 1992, is the first university in Dongguan. It is jointly established by provinces and cities, with cities as the main part. This university seized the historic opportunity of the construction of the GBA and the construction of the Guangzhou-Shenzhen Science and Technology Innovation Corridor. DGUT adhered to the value pursuit of "bringing benefits to the society through excellent innovative educational practice" and the educational concept of "unity of knowledge and practice, morality and cultivate talents". DGUT actively adapted to and supported social and economic transformation and industrial development. DGUT established the training target orientation of high-quality application-oriented innovative talents and deployed the situation of "prominent engineering advantages, distinctive application characteristics and remarkable service results" and actively build a new high-level university of science and engineering that represents the image of Dongguan, a first-class university in China, has international competitiveness and influence. In terms of international development, DGUT insists on "giving priority to ourselves" and has formed the following characteristics:

4.1Construct an extensive and in-depth network of international cooperation

DGUT focuses on future overseas campus construction, international scientific and technological cooperation, offshore incubation, high-level talent gathering, and international exchanges between teachers and students. It takes the overseas innovation center as the carrier, the high-level talent gathering as the breakthrough point, the scientific and technological cooperation innovation and offshore incubation as the breakthrough point, and the customized international exchange and cooperation between teachers and students as the focus. DGUT actively integrates into the global strategy, gathers global innovation resources, and constructs a global cooperation network. Actively expand international cooperation among countries along the B\&R initiative in the Middle East, Africa and the South Pacific, respond to the $B \& R$ initiative, expand the scope and depth of cooperation among universities' overseas institutions, and create a new platform for international cooperation. This university has set up North American Innovation Center, Australian Innovation Center and European Innovation Center through independent establishment, cooperative establishment and joint venture construction. DGUT has also set up branch offices in different cities in the regions where the three innovation centers are located, such as talent workstations, scientific and technological innovation workstations, international innovation and entrepreneurship practice bases, and international joint laboratories (research and development centers), to promote active docking with innovation resources from overseas sources. DGUT vigorously implements a large number of international cooperation projects such as offshore incubation pilot projects, overseas talent introduction projects, virtual international campus projects, overseas scientific and technological cooperation pilot projects, and actively expand multi-domain and multi-mode innovative cooperation with world-class universities in various fields such as personnel training, discipline construction, scientific and technological innovation, and achievement transformation, so as to promote the leapfrog development of various undertakings of the university and enhance the international status, influence and competitiveness.

DGUT has taken the initiative to participate in the construction of university alliance in the GBA. DGUT will deepen its cooperation with well-known universities and industrial parks in the GBA with the future technical characteristic industrial college as the carrier. It will accelerate the formation of a cooperative innovation system with well-known universities in the GBA focusing on the layout of strategic emerging industries in Dongguan, based on the GBA alliance, with the construction of laboratories and scientific and technological research platforms as the starting point, and with the cultivation of applied talents as the breakthrough. DGUT has formulated and promulgated management measures to participate in exchanges and cooperation among prestigious universities in the GBA, deepened cooperation with City University of Hong Kong and Hong Kong Polytechnic University, and built a Bay Area region cooperation platform in 
high-end electronic information, marine bio-medicine, innovative services and other fields relying on Bay Area New District. DGUT will vigorously build scientific and technological cooperation platforms such as Hong Kong-Macao joint laboratories and research centers, and actively promote joint training of doctoral students with prestigious universities in Hong Kong and Macao. The university integrates and utilizes the superior resources of higher education on both sides of the Taiwan Strait, highlights the characteristics of application-oriented personnel training and socialized service, bases itself on Dongguan City, sets up specialties for the industrial development need of the GBA, realizes the powerful combination of superior specialties and disciplines in universities on both sides of the Taiwan Strait, introduces Taiwan's teaching management mode, introduces Taiwan's teaching staff on a full-time basis to undertake teaching and management work, and cultivates high-quality application-oriented innovative talents of cross-specialty, which meet the needs of modern industrial development, be brave in taking on responsibilities. To form a cross-strait higher education integration, local characteristics dominated running characteristics, Guangdong and Taiwan Institute of Technology will be built into a cross-strait higher education cooperation model college.

4.2Push forward multiple, characteristic and cross-border cooperation in running universities and colleges

DGUT has set up a joint college of DGUT and Conservatoire National Des Arts et Métiers (CNAM) . In the process of construction, the joint college DGUT-CNAM Institute has adhered to the principle of self-centered and local internationalization. Besides the relevant specialties in the field of intelligent manufacturing, the joint college has been built into a first-class Chinese-foreign cooperative education institution with distinctive Dongguan industrial characteristics by introducing France's mature training system for engineers, professional teachers, international curriculum system and teaching materials, etc. to create an all-English curriculum system, Sino-French engineers forum, Sino-French joint laboratory, cross-specialty student innovation team, and Sino-French three-stage practical teaching system for engineers. Through innovative measures such as a foreign language center in line with international standards and the establishment of a self-contained English teaching reform system of Sino-French Joint College, English teaching reform will be initiated first in qualified colleges and majors to promote students' foreign language ability and enhance their academic English ability. DGUT will adopt internationally accepted academic performance evaluation methods and standards, introduce internationally leading teaching methods, and set up a wide, in-depth and high-level international talent training exchange and cooperation system. To speed up the development of international education certification for engineering majors, and strive to form a set of scientific and standardized quality standard system that seamlessly interfaces with international engineering education.

DGUT actively participates in the global and regional educational cooperation of international organizations, further promotes the construction of a new mechanism for international colleges, draws lessons from foreign advanced university running concepts, introduces foreign mature international talent training programs, international teachers and international courses to carry out localization training, and explores a new path for international teaching reform. The construction of an international joint campus will be carried out locally, taking the innovation of the mode of jointly constructing the "DGUTNetherlands NHL-Stenden University China Campus" as an opportunity to explore a new mode of international cooperation in running universities locally, and to build a non-entity, non-independent local international cooperation platform. This university has built the new district into an international science and technology cooperation platform cluster that supports and leads industrial innovation and development, a high-end innovative talents cultivation base that meets the requirements of the modern economic system, and an international first-class green wisdom space that meets the needs of future innovation and entrepreneurship through measures such as co-constructing with overseas first-class universities a Chinese-foreign cooperative education institution (one university with multiple specialties, multiple 
universities with multiple specialties), co-constructing disciplines (multiple universities with one discipline), coconstructing laboratories, co-constructing the campus (research institute) of DGUT, and jointly cultivating doctoral students.

\subsection{Create disciplines and subjects which have prominent advantages}

DGUT implements internationalization strategy, international academic standards, abides by internationally accepted academic norms, aims at the dynamic trend of the world's scientific and technological revolution and industrial transformation, takes the national construction of the GBA as an opportunity to create a new type of advantageous and characteristic discipline group in the field of intelligent manufacturing, strengthens the research on ESI ranking system, gives key support to potential disciplines, promotes the upgrading of the university 's new advantageous and characteristic discipline group as soon as possible, and provides a solid discipline foundation and a good discipline ecology for the vigorous promotion of university internationalization. DGUT implements the project of improving the quality of international journal papers, actively guides and strongly supports all teachers and students to publish papers in high-level international academic journals, and strives for more scientific and technological papers to enter SCI Zone 1 and Zone 2. DGUT actively carries out the tracking and operation service of high-quality patents. While digging out key patents and realizing patent agglomeration, DGUT will strengthen the cultivation of PCT international patent applications, strive to increase the number of international patent applications of the university year by year, and strive to demonstrate the innovation strength of the university in the world.

DGUT realizes the substantial operation of the international achievement transformation and innovation platform through the "integration of production and innovation" scientific and technological achievements full-chain transformation system. With the help of the global layout of overseas innovation centers, DGUT will integrate the advantages of innovation resources from overseas sources, interface with the full-chain transformation system of scientific and technological achievements in universities, establish an international achievement transformation innovation platform in line with international standards, build an efficient international achievement transformation service system, gather a group of international professionals to serve the transformation of international achievements, promote the capture of innovation resources from overseas sources, offshore incubation pilot projects, and the introduction and landing of domestic transformation platforms, so as to truly realize the construction of an international achievement transformation innovation platform. This university has explored mutually beneficial cooperation with national scientific research platforms, deeply participated in the construction and operation of platform devices such as China's spallation neutron source, southern synchrotron radiation source and Songshan lake materials laboratory, and conducted research on key common technologies, leading technologies and modern engineering technologies for scientific frontiers. The innovation mechanism will explore the introduction of scientific and technological innovation resources from universities in Hong Kong and Macao and wellknown universities in China. This university will jointly build innovation platforms in high-end electronic information, bio-medicine, innovation services and other fields, jointly declare and undertake scientific and technological projects, and carry out scientific research and transformation of scientific and technological achievements. It will increase the openness of key laboratories, engineering centers and other innovative platforms to society and enterprises.

\section{Conclusion}

Above all, DGUT has grasped the strategic opportunities of the B\&R initiative construction and the GBA, gathered outstanding talents from all over the world, promoted the accelerated gathering of high-quality international resources, created an international cooperation and innovation zone based on first-class standards. DGUT has also strengthened the construction of Chinese-foreign cooperation in running universities and overseas innovation centers, enhanced the level of 
international talent training, constructed a new pattern of all-round internationalization, and continuously improved the international influence and competitiveness. In the future, the new high-level science and engineering universities' internationalization theory and practice should be explored and researched more deeply and thoroughly. On the one hand, this needs macro guidance and strong supports from government and reform policies; On the other hand, it needs our universities' courage to break through and innovate.

\section{References}

[1] Wang K. (2018). Training Practice and Research of Science and Engineering Talents Proposed by Service "Belt And Road Initiative" , Journal of Yunnan Nationalities University (philosophy and social science edition), 2, 154-160.

[2] Xu M. and Huang Y. (2015). The Current Situation and Thinking of the Construction of Foreign Language Culture in University of Science and Engineering from the Perspective of Internationalization, Journal of Northeast Normal University (Philosophy and social sciences edition), 6, 210-213.

[3] Sun J.G. and Liu Y.J. (2013). Construction of International Talent Training Mode in Local Science and Engineering Colleges, Research on Continuing Education, 9, 139-141.

[4] Zhan Y. and Ge X. (2017). Research on the Practice of Ideological and Political Work of Science and Engineering Students from the Perspective of Internationalization of Higher Education, Journal of Jishou University (Social sciences edition), 2, 151-155.

[5] Liu D. (2017). New Interpretation of Cooperative Education in World Class Universities and its Enlightenment to China's B\&R Educational Action, China Higher Education Research, 7, 49-55.

[6] Liu D. and Li Y. (2019). Development of Young Scientific and Technological Talents in the Construction of a New High-level University of Science and Technology: Practical Resistance and Solutions, Think Tank Era, 38, 71-73.

\section{Fund project:}

Dongguan University of Technology's Higher Education Research Project "Research on Internationalization Strategy and Implementation Path of New High-level University of Science and Technology" (Approval Number: 2018GJZD02). 